\title{
Hand-Eye Coordination Using a Video See-Through Augmented Reality System
}

\author{
M. Park ${ }^{*}$, , S. Serefoglou ${ }^{2}$, L. Schmidt ${ }^{3}$, K. Radermacher ${ }^{2}$, C. Schlick ${ }^{1}$ and H. Luczak ${ }^{1}$ \\ ${ }^{I}$ Institute of Industrial Engineering and Ergonomics, RWTH Aachen University, Germany \\ ${ }^{2}$ Medical Engineering, RWTH Aachen University, Germany \\ ${ }^{3}$ Human-Machine Systems Engineering, University of Kassel, Germany
}

\begin{abstract}
The paper describes two experiments for investigating the influence of different levels of camera displacement on hand-eye coordination while using a video see-through head-mounted display. During the first experiment 15 camera positions with five levels of height displacement and three levels of depth displacement were compared in four different tasks. Using a two-way ANOVA, the comparison of the calculated performance characteristic values showed significant influence of height displacement on hand-eye coordination. In conclusion, cameras should be placed above or below eye level, but by no more than $35 \mathrm{~mm}$, in order to preserve hand-eye coordination. In the second experiment, a mirror system was used to check hand-eye coordination in an exemplary medical task allowing the cameras to be placed virtually at eye level. A significant decrease in accuracy was found while using the head-mounted display compared to direct view. Finally, the mirror system was compared to the 15 camera positions using the data from the same tasks. Significant differences in performance were found between the mirror system and eye level position, as well as the position slightly below eye level.
\end{abstract}

The results of the experiment provide design recommendations for developers and users of video see-through systems.

Keywords: Hand-eye coordination, augmented reality, video see-through.

\section{INTRODUCTION}

Augmented Reality (AR) enables the user to communicate intuitively with a combination of real world and supporting computer generated information. For the visual augmentation, different display technologies can be used to merge real world images and synthetic graphics. AR systems can be generally classified as optical see-through (direct view to the surroundings) and video see-through (no direct view, view of video images) [1-4]. Additionally, the displays can be classified as head-mounted (fixed to the user's head) and non head-mounted displays. The advantages and disadvantages of these AR systems are discussed in Azuma [1, 57]. This paper addresses the problems of hand-eye coordination while using a video see-through head-mounted display (HMD) for AR applications.

Such displays are supposed to immerse the user into the scene, which is taken by video cameras and displayed in real time. The user of such a system has no direct view on the environment, but a live-image on the monitors in front of his eyes, which can influence the human perceptual system. The video-based view differs from the natural view in many aspects, for example some depth information is lost, the field of view is relatively narrow and the time lag makes the scene delayed. Moreover, the cameras, which are taking the pictures of the real scene, are located with a certain displacement from the user's eyes, which aggravates the occulomotoric coordination. Time delay and the field of view are

*Address correspondence to this author at the Institute of Industrial Engineering and Ergonomics, RWTH Aachen University, Germany;

E-mail: m.park@iaw.rwth-aachen.de important factors that degrade human performance with video see-through systems. Nichols et al. (1997) [8]; Neveu et al. (1998) [9]; Howarth and Finch (1999) [10]; Adelstein et al. (2000) [11]; Kennedy et al. (1999) [12]; and Nelson et al. (2000) [13] describe the after-effects and fatigue caused by a video see-through HMD. Biocca and Rolland (1998) [14] compared hand-eye coordination with a camera displaced $165 \mathrm{~mm}$ forwards and $62 \mathrm{~mm}$ above user eyes with the performance while having natural sight, as well as the after-effects of such displacement and revealed significant differences. The effects of inter-camera distance and convergence angle on task performance in stereoscopic video seethrough systems are discussed in [15]. In telerobotic applications larger inter-camera separation distances are used, whereas the average interpupillary distance is recommended for AR applications with working distances within arm reach. The sense of presence in synthetic environments as well as the problems of haptics is described in [16-19]. Schmidt and Oehme (2007) [20] discuss the problems of depth perception in video-based view. Particularly, they state that the users of such systems tend to overestimate the distance of synthetic objects. Pichler et al. (1997) [21] describes the influence of stereoscopic visualization on endoscopic manipulations. The authors state that dexterity and positioning accuracy of endoscopically guided manipulations can be significantly improved while using a 3D video endoscopic system compared to monocular systems.

Nevertheless, video see-through displays have certain advantages, even as new issues arise from the need to create an effective camera system which would allow a good handeye coordination. The use of closed view displays is especially advantageous in the application areas where the eyes 
need to be protected from physical or chemical hazards, such as small flying particles, dangerous substances or radiation. An additional advantage of such displays is the possibility to improve the quality of the video stream of the cameras. An example is the use of video see-through displays for metal gas arc welding [22]. The closed view display protects the user's eyes from the UV-radiation. In addition, by using some image processing algorithms, the light intensity of the bright arc radiation can be reduced in the picture, providing a better view. Using AR technology, some supportive information about the geometry of the welded parts and relevant process information can be overlapped on the improved real view taken by the cameras.

Similarly, video see-through displays are also used in medical applications. During laparoscopic operations, the surgeon views the endoscopic image on a monitor - monoscopically, stereoscopically (e.g. using shutter or polarized glasses) or autostereoscopically. Today the option to use HMDs is offered by many commercial system providers for surgical endoscopy, microscopy and computer assisted surgery. The use of HMDs and AR for laparoscopy has been investigated by $[23,24]$. HMDs can also provide the image from an extracorporal stereoscopic camera, as in a semirobotic exoscope manipulator system [25] and a digital microscope [26].

\section{MATHERIALS AND METHODOLOGY}

\section{Experimental Design and Equipment}

The aim of this research is to study the differences in hand-eye coordination with different camera positioning using a video see-through display.

Experiment 1: During the first experiment, the cameras were placed at 15 different positions with a certain level of vertical and horizontal displacement from the user's natural eye position (see Fig. (1) and Table 1).

The experiment was carried out in three steps. During each step five camera positions were tested. During the first step, all five camera positions were set with the depth displacement of $130 \mathrm{~mm}$, during the second step $165 \mathrm{~mm}$ and during the third step $200 \mathrm{~mm}$. For each step, 20 subjects performed experimental tasks with the five camera positions, in total 60 subjects for the entire experiment. The order of starting camera position was counterbalanced over the subjects.

In order to compare the five camera height displacements during each step, a within subject design was chosen, whereas to test the depth displacement a between subjects design was chosen (performance between three different groups was compared). This kind of mixed design was chosen under the consideration of the subjects' workload.

Summarising the experimental design, the group of 20 subjects for each of the three depth variations had to perform the same four tasks with each of the five camera positions. Additionally, each subject had to perform the four experimental tasks without HMD and cameras, having natural sight. The subjects were also asked to indicate the best and the worst camera positions.

Table 1. Levels of Height and Depth Displacement for Each Camera Position

\begin{tabular}{|c|c|c|}
\hline $\begin{array}{c}\text { Camera } \\
\text { Position }\end{array}$ & $\begin{array}{c}\text { Height Displacement Above (+) } \\
\text { or Below (-) the Eye Level }\end{array}$ & $\begin{array}{c}\text { Depth Displacement } \\
\text { from Eye Level }\end{array}$ \\
\hline \hline $\mathrm{CP} 1 / \mathrm{CP} 5$ & $+70 \mathrm{~mm} /-70 \mathrm{~mm}$ & $130 \mathrm{~mm}$ \\
\hline $\mathrm{CP} 2 / \mathrm{CP} 4$ & $+35 \mathrm{~mm} /-35 \mathrm{~mm}$ & $130 \mathrm{~mm}$ \\
\hline $\mathrm{CP} 3$ & $0 \mathrm{~mm}$ & $130 \mathrm{~mm}$ \\
\hline $\mathrm{CP} 6 / \mathrm{CP} 10$ & $+70 \mathrm{~mm} /-70 \mathrm{~mm}$ & $165 \mathrm{~mm}$ \\
\hline $\mathrm{CP} 7 / \mathrm{CP} 9$ & $+35 \mathrm{~mm} /-35 \mathrm{~mm}$ & $165 \mathrm{~mm}$ \\
\hline $\mathrm{CP} 8$ & $0 \mathrm{~mm}$ & $165 \mathrm{~mm}$ \\
\hline $\mathrm{CP} 11 / \mathrm{CP} 15$ & $+70 \mathrm{~mm} /-70 \mathrm{~mm}$ & $200 \mathrm{~mm}$ \\
\hline $\mathrm{CP} 12 / \mathrm{CP} 14$ & $+35 \mathrm{~mm} /-35 \mathrm{~mm}$ & $200 \mathrm{~mm}$ \\
\hline $\mathrm{CP} 13$ & $0 \mathrm{~mm}$ & $200 \mathrm{~mm}$ \\
\hline
\end{tabular}

Experiment 2: In addition, the second hand-eye coordination experiment was carried out with a mirror-camera-HMD system (Fig. 2), which allows placing the cameras virtually at the eye level. The system was tested with the workers of biomedical technology institute, using a skull model. The aim was to check the hand-eye coordination using such a system under realistic working conditions in the image guided surgery.

In order to acquire a video image as seen through the natural position and orientation of the eyes, the mirror system shown in the left part of Fig. (2) was developed and mounted on the HMD [27]. A pair of mirrors place the apparent centroid of each camera in the same location as the centre of the respective eye when the HMD is properly fitted to the user $[23,24]$. The solid outlines in the right part of
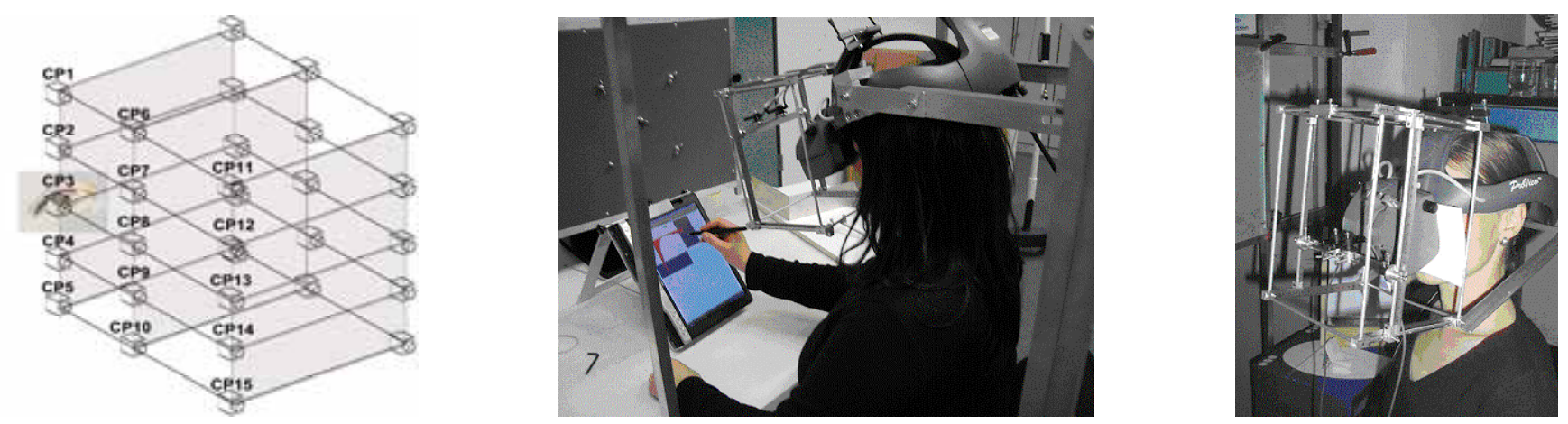

Fig. (1). Camera placement model and fixation equipment. 
Fig. (2) correspond to the right camera and its real, folded frustum (pyramid). The dashed outlines correspond to its virtual position and its unfolded frustum, coinciding with the position and frustum of the right eye. Because of the frustum geometry, the required dimensions of the lower (and larger) mirror are proportional to its distance from the eyes, for a given inclination to the optical axis. Therefore, a flatter HMD would allow a more compact and thus preferable future design. It is also possible to use separate mirror pairs for each eye.

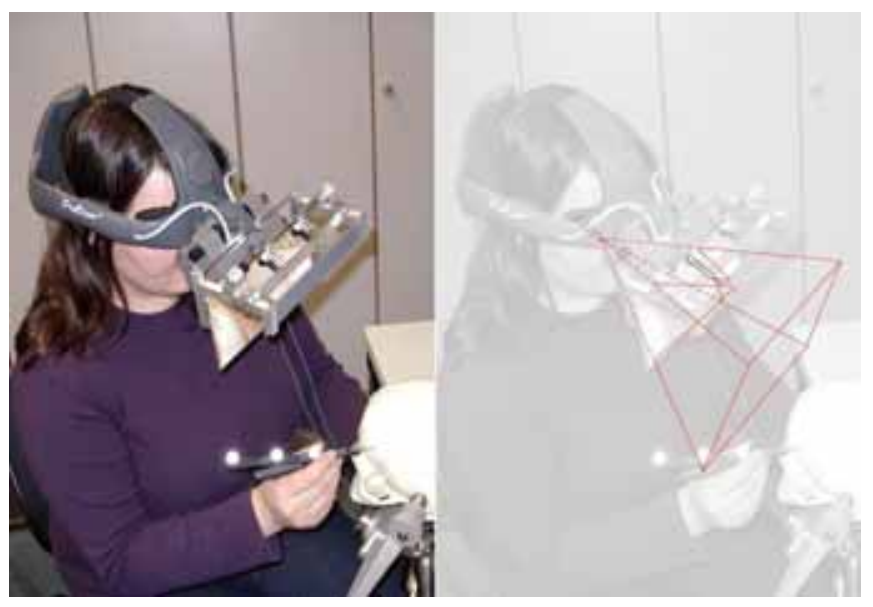

Fig. (2). Mirror system and right camera frustum.

A Polaris System (NDI, Ontarion, Canada) was used for both experiments to optically track the relative position of the handheld stylus to the fixed basis in 3D space, each of both carrying a rigid body with 3 retroreflective spherical markers. The system utilizes two cameras and infrared illumination to measure the position of these markers through triangulation. The position and orientation of the rigid bodies is then calculated by matching their given individual geometries with the markers. Tracking occurs in real-time with approximately 30 measurements per second.

A video see-through HMD (Kaiser ProViewXL) with a resolution of $1024 \times 768\left(\mathrm{FOV}^{\circ} 0^{\circ}\right)$ was used during both experiments. Two miniature cameras (Toshiba ACM 413 E) were used to capture the real scene, which was played on the HMD. Head tracking, image processing or overlapping of computer graphics were not applied to this system, in order to keep time lag at a minimum and to reduce additional influencing factors. For this research a constant camera separation distance of $64 \mathrm{~mm}$, which is the average interpupillary distance for human eyes [28], was set for all experimental conditions. In order to enable stereopsis, a convergence angle of $4^{\circ}$ was calculated for each camera at a constant distance of 458 $\mathrm{mm}$ to the working area. It is known that performance with stereoscopic video-see-through HMD is the best when the optical axes of the two cameras intersect at the working plane. If the focus point is behind or in front of the plane, it becomes difficult to focus on the target at the working plane [29]. In order to keep the focusing point of the cameras at the working plane, the HMD with the camera-fixation equipment was fixed to a special construction (Fig. 1), which allowed only the slight head turning to the left and right. The height of the HMD and the tilting angle were adjusted for each task and for each subject individually so that the working area was basically visible without moving the head.

\section{Experimental Tasks}

During the experimental tests described in this paper, hand-eye coordination accuracy and time on task were measured using different types of experimental tasks:

\section{Tracing Lines on a Touch Screen (Fig. 3a)}

Six different shapes of straight and angular lines appeared in random order on the touch screen, each a total of three times. Test participants had to trace the original line with a tracked pen-shaped stylus. Time and accuracy were measured in order to assess the subjects' performance. In order to calculate the deviation factor, the deviation area between the original line and repeated line was summed and divided by the length of the line. Performance time was measured from the first contact of the stylus with the touch screen surface within the "start" area to the loss of the contact, when the stylus was in the "finish" area.

This type of task imitates hand activity in many types of real tasks, where users have to repeat straight and angular lines with an instrument.

\section{Placing the Stylus Over a Dot on the Touch Screen (Fig. 3b)}

The dots appeared at a randomly computer selected area on a touch screen, each in total three times. The distance between the dot and the pointed area as well as the time from the appearance of the dot till the placement of the stylus on the touch screen were assessed. This type of task is related to the manual targeting tasks.

\section{Tracing the Edge of a Metal Sheet (Fig. 3c)}

The third task was similar to that of line tracing on a touch screen, however it measured deviation in the $X, Y$ and $\mathrm{Z}$ directions (measurement accuracy $0,2 \mathrm{~mm}$ ). The subjects had to trace the $726 \mathrm{~mm}$ long and 1,5 mm thick edge of a metal sheet with a tracked stylus a total of six times for each experimental condition. The deviation volume was calculated from the $\mathrm{X}, \mathrm{Y}$ and $\mathrm{Z}$ deviations and divided by the length of the track. The tracing direction left-to-right or right-to-left was counterbalanced.

This edge tracing task on a 3D object can be compared to the skull milling task using image guided surgery, where the surgeon has to follow a predefined virtual path.

\section{Screwing Wingnuts on an Assembly Board (Fig. 3d)}

During the fourth task the subjects had to screw five wingnuts, which were located within an area of $18 \times 18 \mathrm{~cm}$. The subjects were using only the dominant hand. The time for screwing each wingnut was measured. The wingnut screwing task refers to the manual assembly.

\section{Tracing a Pre-Defined Path on a Skull-Model (Fig. 2)}

The subjects had to follow with a stylus a C-shaped path on the left half of the frontal bone, which was outlined and registered using the tracked pointer. The experimental task was to drag the pointer along this path, simulating milling during maxillofacial surgery. This task was repeated 12 times for each of the two conditions (with mirror system and with natural sight) and the data was averaged. 
(a)

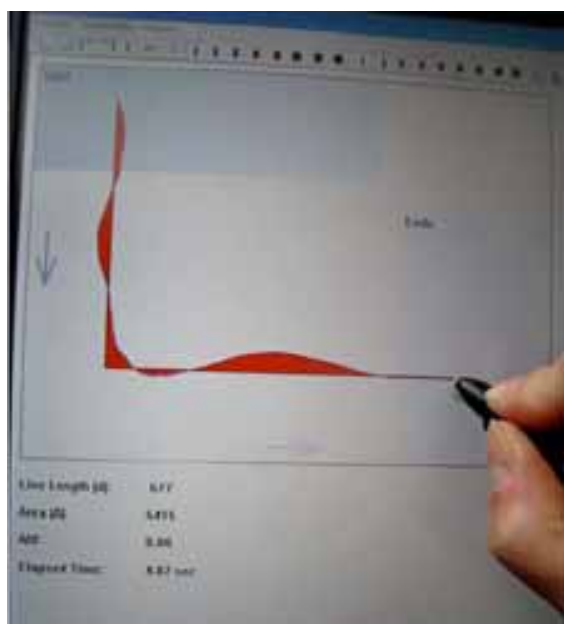

(b)

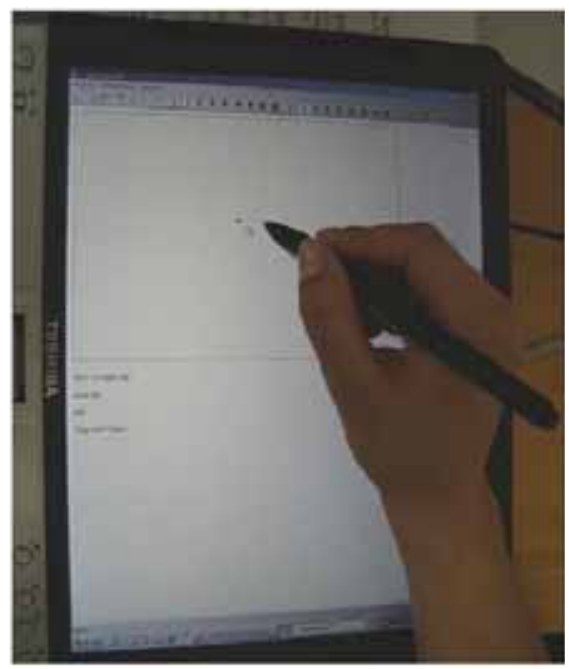

(c)

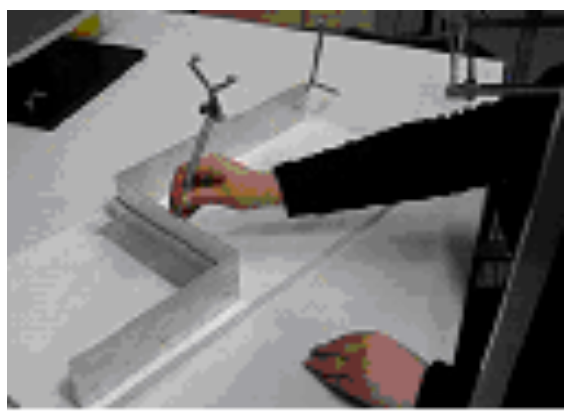

(d)

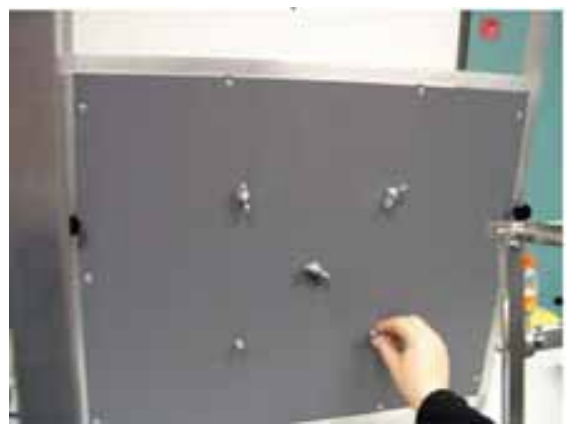

Fig. (3). Experimental tasks.
The tasks 1, 2, 3 and 4 were used for the first experiment (15 camera displacement positions) and the tasks 1,2 and 5 were used for the second experiment (mirror system virtually placing the cameras at the eye level).

\section{Subjects}

60 volunteers (25 females and 35 males) between the ages of 19 and 45 participated in the first experiment. For each experimental step a group of 20 subjects performed the tasks with five camera positions. The first group tested camera positions 1-5, the second group the positions 6-10 and the third group the positions 11-15.

During the second experiment, 26 employees of an institute of biomedical technology (4 females and 22 males) between the ages of 22 and 38 participated testing the mirror system and evaluated its possibilities to be applied in image guided surgery.

All participants in both experiments were right handed. Only the subjects having normal or corrected-to-normal vision as well as acceptable visual acuity (angle of stereopsis of at least 100 seconds) could participate in the tests. Each subject's vision was tested with a Bernell-o-Scope apparatus and screening tests.

\section{RESULTS}

\section{Experiment 1}

Camera Positions. A performance characteristic value (PCV) was calculated for each position. The time data and deviation data for each task were normalized within a scale of 0 to 10 , summarised and averaged. In order to calculate the PCV, the characteristic values for each camera position were subtracted from the largest possible value so that the larger number of PCV indicated better performance in terms of accuracy and time. It was observed that the subjects tended either to work fast and less accurate or slower and more accurate during each task [30-32]. The calculated PCV considers the effects of camera positioning on both variables: time and accuracy, which were weighted equally. All data was checked for normal distribution (Kolmogorov-Smirnov test). No significant deviation from the normality was found. The Mauchly's sphericity test showed significant results (Mauchly-W $=0.895$, df =9, p =0.002). Therefore, HuynhFeldt correction was used with mixed ANOVA (withinsubject and between-subject). The level of significance was set to $\alpha=0.05$.

The interaction between height and depth displacement was not significant $(\mathrm{p}>0.05)$ (Table 2$)$. The height displacement showed a significant effect with $F(4,20)=3.356$, $\mathrm{p}=0.01$, whereas the effect of depth displacement was with $\mathrm{p}>0.05$ not significant.

The effect of height displacement was further analyzed with a posteriori Bonferroni-Tests. Fig. (4) shows the changes in PCV depending on height displacement with constant depth of $130 \mathrm{~mm}$ (depth level 1). The differences between the camera positions CP1 - CP2 $(\mathrm{t}=2.981, \mathrm{p}=0.004)$, $\mathrm{CP} 1-\mathrm{CP} 4(\mathrm{t}=2.213, \mathrm{p}=0.03)$ and $\mathrm{CP} 2-\mathrm{CP} 3(\mathrm{t}=-2.009$, $\mathrm{p}=0.048)$ were significant.

Fig. (5) shows PCV differences in the second depth displacement level $(165 \mathrm{~mm})$. Significant differences were 
found between the positions (CP6) - (CP7) $(\mathrm{t}=2.047$, $\mathrm{p}=0.04)$.

Table 2. Depth and height displacement effects (ANOVA results)

\begin{tabular}{|l|c|c|c|c|}
\hline \multicolumn{1}{|c|}{ Source } & df & SS & MS & F \\
\hline \hline Between-Subject & 234 & & & \\
\hline Depth displacement & 2 & 144.62 & 72.31 & 1.94 \\
\hline Error (Between-Subject) & 232 & 8631.0 & 37.2 & \\
\hline Within-Subject & 940 & & & \\
\hline Height displacement & 4 & 63.6 & 15.9 & $3.356^{*}$ \\
\hline Height×Depth & 8 & 13.44 & 1.68 & 0.354 \\
\hline Error (Within-Subject) & 928 & 4274.31 & 4.616 & \\
\hline Total & 1174 & 13126.97 & & \\
\hline$*$ p $<0.05$ (significant). & & &
\end{tabular}

*p $<0.05$ (significant).

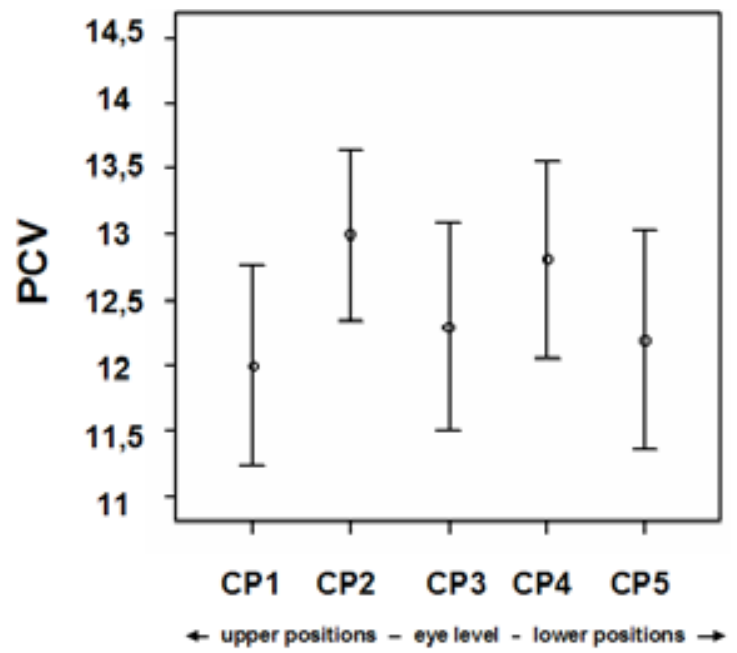

Fig. (4). Performance Characteristic Values with the depth displacement of $130 \mathrm{~mm}$ (mean values and 95\%-confidence intervals).

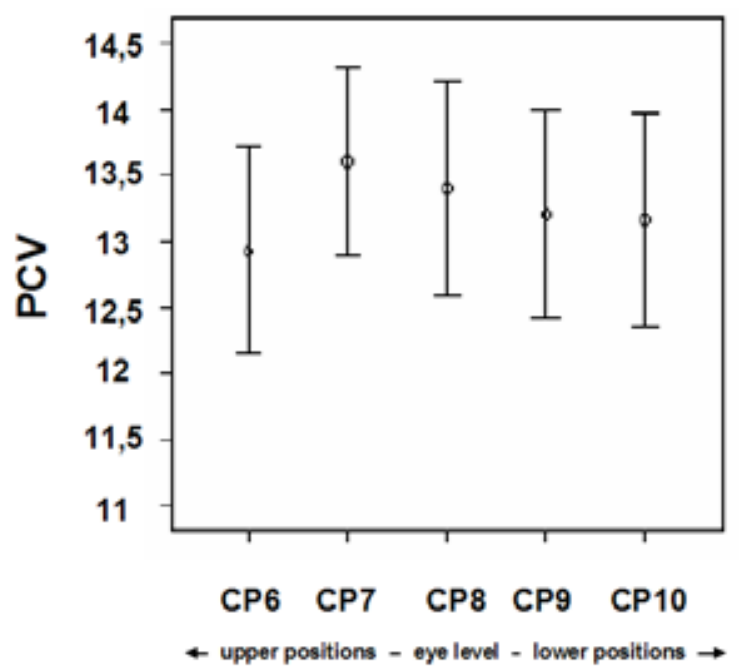

Fig. (5). Performance Characteristic Values with the depth displacement of $165 \mathrm{~mm}$ (mean values and 95\%-confidence intervals).

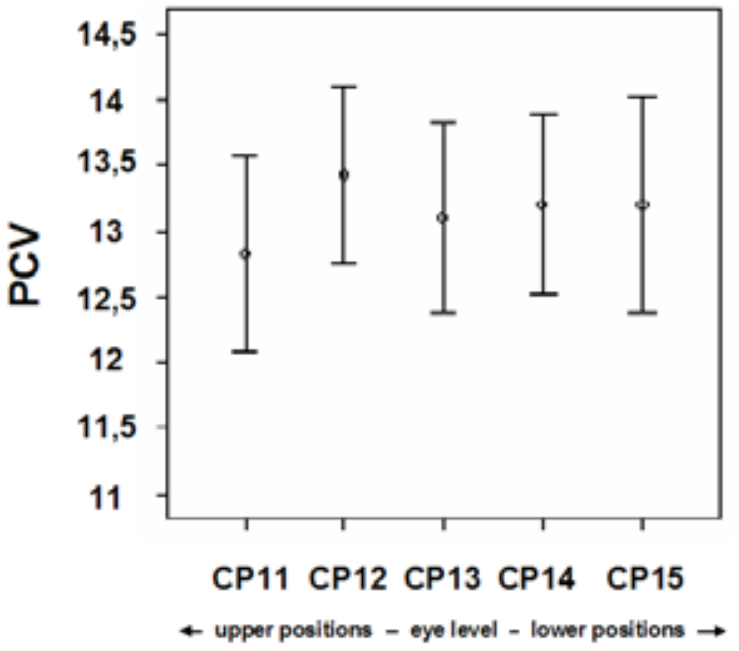

Fig. (6). Performance Characteristic Values with the depth displacement of $200 \mathrm{~mm}$ (mean values and 95\%-confidence intervals).

In the third depth displacement level $(200 \mathrm{~mm})$ similar effects were revealed. Significant difference was found between positions CP11 - CP12 ( $\mathrm{t}=2.025, \mathrm{p}=0.046)$ (Fig. 6).

Table 3. Depth and Height Displacement Effects (ANOVA Results)

\begin{tabular}{|c|c|c|c|c|c|c|c|}
\hline \multirow{3}{*}{$\mathbf{C P}_{\mathbf{i}}$} & \multicolumn{7}{|c|}{ Task } \\
\hline & \multicolumn{2}{|c|}{$\begin{array}{l}\text { Tracing } \\
\text { Lines }\end{array}$} & \multicolumn{2}{|c|}{$\begin{array}{l}\text { Placing Stylus } \\
\text { Over Dots }\end{array}$} & \multicolumn{2}{|c|}{$\begin{array}{l}\text { Tracing } \\
\text { Edge }\end{array}$} & \multirow{2}{*}{$\begin{array}{c}\begin{array}{c}\text { Screwing } \\
\text { Wingnuts }\end{array} \\
\text { Time }\end{array}$} \\
\hline & Accuracy & Time & Accuracy & Time & Accuracy & Time & \\
\hline CP1 & $-26 \% *$ & $+2 \%$ & $-31 \% *$ & $+17 \%$ & $-36 \% *$ & $+34 \%$ & $+28 \% *$ \\
\hline CP2 & $-25 \% *$ & $+0,4 \%$ & $-24 \% *$ & $+13 \%$ & $-31 \% *$ & $+23 \%$ & $+22 \% *$ \\
\hline CP3 & $-27 \% *$ & $+2 \%$ & $-28 \% *$ & $+11 \%$ & $-32 \% *$ & $+51 \%$ & $+33 \% *$ \\
\hline CP4 & $-23 \% *$ & $+4 \%$ & $-31 \% *$ & $+3 \%$ & $-27 \% *$ & $+25 \%$ & $+26 \% *$ \\
\hline CP5 & $-28 \% *$ & $-6,1 \%$ & $-31 \% *$ & $+10 \%$ & $-33 \% *$ & $+53 \%$ & $+25 \% *$ \\
\hline CP6 & $-30 \% *$ & $-11 \%$ & $-25 \%$ & $+24 \%$ & $-21 \% *$ & $-7 \%$ & $+41 \% *$ \\
\hline CP7 & $-32 \% *$ & $-15 \%$ & $-33 \% *$ & $+33 \% *$ & $-17 \%$ & $-12 \%$ & $+38 \% *$ \\
\hline CP8 & $-27 \% *$ & $-11 \%$ & $-17 \%$ & $+34 \% *$ & $-15 \%$ & $-13 \%$ & $+31 \% *$ \\
\hline CP9 & $-28 \% *$ & $-6 \%$ & $-33 \% *$ & $+27 \%$ & $-14 \%$ & $-6 \%$ & $+35 \% *$ \\
\hline CP10 & $-25 \% *$ & $-7 \%$ & $-33 \% *$ & $+27 \%$ & $-20 \% *$ & $-8 \%$ & $+39 \% *$ \\
\hline CP11 & $-27 \% *$ & $-14 \%$ & $-8 \% *$ & $+22 \%$ & $-27 \%$ & $-6,8 \%$ & $+36 \% *$ \\
\hline CP12 & $-20 \% *$ & $-7 \%$ & $-15 \% *$ & $+18 \%$ & $-22 \%$ & $-7 \%$ & $+29 \% *$ \\
\hline CP13 & $-25 \% *$ & $-11 \%$ & $-4 \% *$ & $+5 \%$ & $-30 \%$ & $-5 \%$ & $+28 \% *$ \\
\hline CP14 & $-20 \% *$ & $-6 \%$ & $-7 \% *$ & $+15 \%$ & $-26 \%$ & $-4 \%$ & $+30 \% *$ \\
\hline CP15 & $-21 \% *$ & $-14 \%$ & $-2 \% *$ & $+18 \%$ & $-31 \%$ & $-5 \%$ & $+31 \% *$ \\
\hline
\end{tabular}

$* \mathrm{p}<0.05$ (significant).

Speed and Accuracy. Additionally, performance with video see-through display was compared with performance while having natural sight. It was observed that in most of the cases performance was less accurate while wearing an HMD; however, in some cases the subjects tended to work faster while wearing HMD. Table 3 summarizes the changes in accuracy (less deviation refers to better accuracy) and 
performance time for each task and each camera position in percent.

Subjective Ratings. For each depth displacement level the subjects were asked to indicate the most preferred camera position and the worst position. In the first level CP4 was favored by the majority of the subjects and CP1 was perceived to be the worst position. In the second level all positions with the exception of CP6 (was perceived to be the worst) were rated about the same. In the third level the most favorite positions were $\mathrm{CP} 12$ and $\mathrm{CP} 13$, whereas the rest of the positions were neutral.

\section{Experiment 2}

Tracing the pre-defined path on the skull model. The Kolmogorov-Smirnov test did not show significant deviation of the collected data from normality, therefore t-test was used for analyzing the data.

Significant differences were found when comparing performance with the mirror system to performance with the natural sight. The subjects could perform more accurately while having natural sight than with the mirror system $(\mathrm{t}=$ $2.350 ; p=0.027)$; however, no difference was found in time between the two conditions $(t=-.936 ; \mathrm{p}=0.358)$ (Fig. 7).

\section{Comparison of Experiment 1 and 2}

The data collected during the experiments with the mirror system while performing line tracing and dot targeting tasks were compared to the data of the same tasks from the experiment with displaced cameras. Particularly, the camera position with 0 depth and height displacement ( $\mathrm{CP} 0$ - mirror system) was compared to the 15 different levels of camera displacement. Significant differences in terms of time were revealed between $\mathrm{CP} 0$ and $\mathrm{CP} 13(\mathrm{t}=-2.337 ; \mathrm{p}<0.05)$ as well as $\mathrm{CP} 0$ and $\mathrm{CP} 14(\mathrm{t}=-2.06 ; \mathrm{p}<0.05)$ during the dot targeting task (Fig. 8). Test participants performed faster with the mirror system than with these two particular positions of displaced cameras. No significant differences were found in terms of accuracy.

\section{DISCUSSION AND CONCLUSIONS}

The results of the experiments showed a significant influence of camera height displacement in the stereoscopic video see-through AR system. The subjects showed significantly worse performance with the height displacement of 70 $\mathrm{mm}$ than with the height displacement of $35 \mathrm{~mm}$ above users' eyes for all three levels of depth displacement $(130 \mathrm{~mm}$, $165 \mathrm{~mm}$ and $200 \mathrm{~mm}$ ). Surprisingly, performance with the height displacement of $35 \mathrm{~mm}$ was significantly better than performance with cameras placed at eye level with $130 \mathrm{~mm}$ depth displacement. Additionally, for the other two depth displacement levels subjects did not perform significantly better with cameras at eye level as it was expected. While performing with cameras at eye level, subjects obscured the view of the target with their fingers or hand. The cameras with the height displacement of $35 \mathrm{~mm}$ above or below eye level were taking the view from a slightly upper or lower position, which was probably a more comfortable view, avoiding the occlusion of the target or object to be manipulated. Conversely, the extreme upper and lower positions, which were also taking a non-covered view, were not so comfortable positions as they were too far from eye level and the visuo-motoric system could not adjust as well to the shifted view [13] state that the human visuo-motoric system can adjust to certain levels of displacement. However, it becomes more difficult to adjust with the increasing height displacement, so that the extreme upper position with $70 \mathrm{~mm}$ significantly differs in terms of performance. No significant effects of depth displacement were found during this experiment.

For all experimental tasks and for all camera positions a decrease in accuracy was found while performing with the HMD compared to the performance without the HMD. For most of the tasks and positions the decrease was significant; however, during some tasks the subjects tended to work faster with the HMD, which led to a lower accuracy. Even with the mirror system which allowed the cameras to be placed at eye level, significant differences were found between performance accuracy with the HMD and without the HMD. These findings implicate the strong effect of other system related factors on performance, such as the restricted field of view, weight of the HMD, absence of depth cues, time lag etc.

Comparing the mirror system to the HMD with 15 different camera positions, significant differences in time were
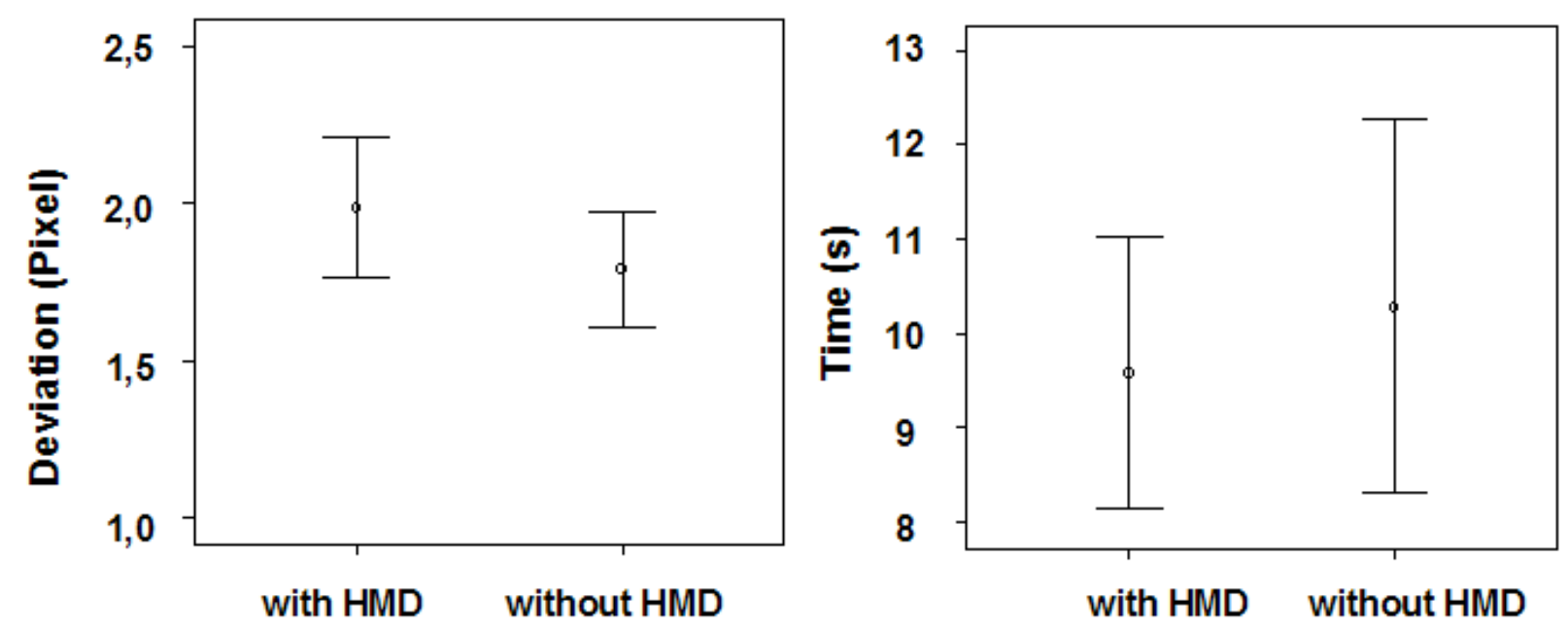

Fig. (7). Task performance with the mirror system compared to performance with natural view. 


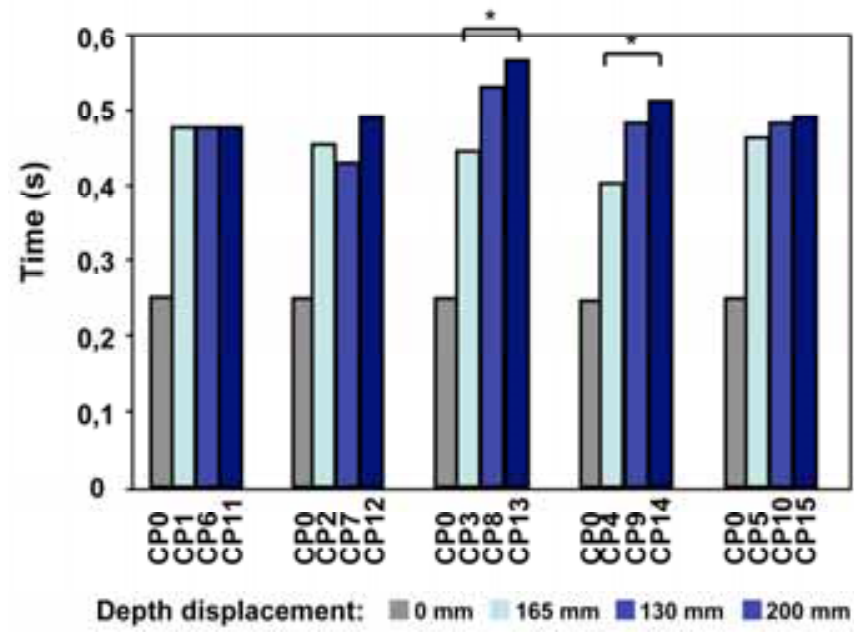

*significance $(p<0.05)$

Fig. (8). Comparison of the mirror system and conventional camera HMD with different camera positions (dot targeting tasks).

found while performing with cameras at eye level and 35 $\mathrm{mm}$ below eye level with a depth displacement of $200 \mathrm{~mm}$. The subjects could perform faster with the mirror system. These results implicate a certain improvement of the mirror system compared to the system with displaced cameras. However, no significant differences in accuracy were observed.

Due to the limitations of current technology, it is still difficult to create a video-based view, which can perfectly emulate the natural view of human eyes; however, in order to eliminate the adverse effects of height displacement, the cameras should not be placed more than $35 \mathrm{~mm}$ above or below user eye level, which is often the case in AR applications. As the results indicate, placement of cameras over or below those levels negatively affects hand-eye coordination.

As mentioned before, during this study a head fixation apparatus was used to keep a constant distance to the working plane for all subjects during each task. It might have influenced the results to some extent. During the tasks in these experiments, the subjects had haptic feedback so that the hand-coordination was not only based on vision; however, during most of the tasks in industry the users of AR systems do have haptic feedback as well. No control helmet was applied while performing tasks without the HMD, so that the influence of field of view or the weight of the HMD was not considered. The aim was to compare the performance under natural conditions with the performance while wearing a video see-through HMD.

In order to improve hand-eye coordination with videobased view, other system related factors, such as field of view, weight of HMDs, time lag etc. should be systematically studied. Especially it is important to check the effects of interaction between different system components. Further research is needed in order to create a video see-through system that meets the high standards of medical applications.

\section{ACKNOWLEDGEMENTS}

The research was supported by the Holste-Foundation (RWTH Aachen).

\section{REFERENCES}

[1] Azuma RT. A survey of augmented reality. In: Presence: Teleoperators and Virtual Environments. MIT Press, Cambridge, USA 1997; 6: pp. 355-85.

[2] Milgram P, Colquhoun H. A Taxonony of real and virtual world display integration. In: Ohta Y, Tamura H, Eds. Mixed Reality Merging Real and Virtual Worlds. Springer, Berlin, Germany 1999.

[3] Luczak H, Schmidt L, Oehme O, Rötting M. Visual Displays in Human-Computer Interaction. In: Karwowski W, Ed. International encyclopedia of ergonomics and human factors. Taylor \& Francis, Boca Raton 2006; pp. 1508-11.

[4] Wiedenmaier S, Oehme O, Schmidt L, Luczak H. Augmented reality for assembly processes - design and experimental evaluation. In: Int J Hum Comput Interact Erlbaum, Mahwah, NJ 2003; 16: pp. 497-514.

[5] Fuchs H, Ackermann J. Displays for augmented reality: historical remarks and future Prospects. In: Ohta Y, Tamura H, Eds. Mixed Reality - Merging Real and Virtual Worlds. Springer, Berlin, Germany 1999.

[6] Oehme O, Schmidt L, Luczak H. Comparison between the strain indicator HRV of a head-based virtual retinal display and LC headmounted displays for augmented reality. Int J Occup Saf Ergon 2003; 9: pp. 419-43.

[7] Park M, Schmidt L, Schlick C, Luczak H. Design and evaluation of an augmented reality welding helmet. In: Hum Factors Ergon Manufacturing 2007; 17: 317-30.

[8] Nichols S, Cobb S, Wilson JR. Health and safety implications of virtual environments: measurement issues. In: Presence: teleoperators and virtual environments. MIT Press, Cambridge, USA, 1997; 6: pp. 667-75.

[9] Neveu C, Blackmon T, Stark L. Evaluation of the effects of a headmounted display on ocular accommodation. In: Presence: teleoperators and virtual environments. MIT Press, Cambridge, USA 1998; 7: pp. 278-89.

[10] Howarth PA, Finch M. The Nauseogenicity of two methods of navigation within a virtual environment, Applied Ergonomics, UT, USA 1999; pp. 39-45.

[11] Adelstein BD, Elis SR, Jung JY. Discriminability of prediction artifacts in a time-delayed virtual environment. In: Proceedings of 44th Annual Meeting of the Human Factors and Ergonomic Society. Santa Monica, CA, USA 2000: pp. 499-502.

[12] Kennedy RS, Lanham DS, Drexler JM, Massey CJ, Lilienthal MG. A comparison of cybersickness incidences, symtom profiles, measurement techniques and suggestions for further reseach. In: Presence: Teleoperators and Virtual Environments. MIT Press, Cambridge, USA 1997; 6: pp. 638-44.

[13] Nelson WT, Roe MM, Bolia RS, Morley RM. Assessing simulator sickness in a see-through HMD: effects of time delay, time on task, and task complexity. In: Proceedings of Image 2000 Conference, Scottsdale, AZ, USA 2000.

[14] Biocca FA, Rolland JP. Virtual eyes can rearrange your body: adaption to visual displacement in see-through, head-mounted displays. In: Presence: Teleoperators and virtual environments. MIT Press, Cambridge, USA 1998; 7: pp. 262-77.

[15] Luczak H, Park M, Balazs B, Wiedenmaier S, Schmidt L. Task performance with a wearable augmented reality interface for welding. In: Proceedings of HCII. Erlbaum, Mahwah, NJ 2003: pp. 98102 .

[16] Burdea GC. Haptic issues in virtual environments. IEEE Computer Graphics International, Geneva, Switzerland 2000; pp. 259-302.

[17] Biocca F, Kim J, Choi Y. Visual touch in virtual environments: an exploratory study of presence, multimodal interfaces, and crossmodal sensory illusions. In: Presence: Teleoperators and Virtual Environments. MIT Press, Cambridge, USA 2001; 10: pp. 247-65.

[18] Gaggioli A, Breining R. Perception and cognition in immersive virtual reality. In: Riva G, Davide F, Eds. Communications through virtual technology: Identity community and technology in the internet age, IOS Press, Amsterdam, Netherlands 2001; pp. 71-86.

[19] Hu HH, Gooch A, Creem-Regehr S, Thomson W. Visual cues for perceiving distances from objects to surfaces. In: Presence: Teleoperators and Virtual Environments. MIT Press, Cambridge, USA 2002; 11: 652-64.

[20] Schmidt L, Oehme O. Physiological Limits of Human Visual Perception in Virtual Environments. In: Computing Systems for $\mathrm{Hu}-$ man Benefits : Proceedings of the 8th International Conference on Work With Computing Systems, Toomingas, A., Lantz, A., Berns, 
T. (Eds.), Royal Institute of Technology, Stockholm 2007; pp. 2537.

[21] Pichler CV, Radermacher K, Rau G. Stereoscopic visualisation in endoscopic surgery - problems, benefits, potentials. In: Presence: Teleoperators and Virtual Environments. MIT Press, Cambridge, USA 1997; 6: pp. 198-217.

[22] Hillers B, Aiteanu D, Tschirner P, Park M, Gräser A, Balazs B, Schmidt L. TEREBES: welding helmet with AR capabilities. International Status Conference: Virtual and Augmented Reality, Leipzig, Germany 2004.

[23] Fuchs H, Livingston AM, Raskar R, Colucci D, Keller K, State AJ, Crawford JR, Rademacher P, Drake SH, Meyer AA. Augmented reality visualization for laparoscopic surgery. In: Proceedings of First International Conference on Medical Image Computing and Computer-Assisted Intervention, MIT, Cambridge, MA, USA 1998.

[24] State A, Keller K, Rosenthal M, Yang H, Ackerman J, Fuchs H. Stereo imagery from the UNC augmented reality system for breast biopsy guidance. In: Medicine Meets Virtual Reality, Newport Beach, CA 2003.

[25] Serefoglou S, Lauer W, Perneczky A, Lutze T, Radermacher K. Multimodal user interface for a semi-robotic visual assistance system for image guided neurosurgery. In: CARS 2005- Computer Assisted Radiology and Surgery, Berlin, Germany 2005.
[26]

Serefoglou S, Park M, Radermacher K, Schmidt L. Untersuchung der Hand-Auge-Koordination bei einem videobasiertenSpiegelHMD.In: Urbas L \& Steffens C (Hrsg.). Zustandserkennung und Systemgestaltung -6. Berliner Werkstatt Mensch-MaschineSysteme, ZMMS Spektrum Band 19 Fortschritt-Berichte VDI Reihe 22, Nr. 22. Düsseldorf: VDI Verlag.

[27] Varvaro H, Lizandra MCJ, Raya MA, Monserrat C, Grau V, Gil JA. Digital microscope with augmented reality for neurosurgery In: CARS 2001- Computer Assisted Radiology and Surgery. Berlin, Germany 2001; pp. 248-53.

[28] Dodgson NA. Variation and extrema of human interpupilary distance. In: Proceedings of SPIE. San Jose, CA, USA, 2004; Vol. 5291: 36-46.

[29] Drascic D, Milgram P. Perceptual issues in augmented reality. In Proceedings of SPIE, Vol 2653 "stereoscopic displays and virtual reality systems III”, San Jose (CA) USA 1996; pp. 123-34.

[30] Fitts PM. The information capacity of the human motor system in controlling the amplitude of movement. J Exp Psychol 1954; 47 : 381-91.

[31] MacKenzie IS, Buxton W. The prediction of pointing and dragging times in graphical user interfaces. Interact Comput 1994; 6: 213-27.

[32] Wickens CD. Human factors in vector map design: the importance of task-display dependence. J Navigation 2000; 53: 54-67.

(C) Park et al.; Licensee Bentham Open.

This is an open access article licensed under the terms of the Creative Commons Attribution Non-Commercial License (http://creativecommons.org/licenses/bync/3.0/) which permits unrestricted, non-commercial use, distribution and reproduction in any medium, provided the work is properly cited. 